\title{
Terapia endovascular en trauma periférico. Una alternativa a la cirugía abierta tradicional
}

\author{
Juan Marín P. ${ }^{1,2}$, Ricardo Olguín L. ${ }^{2}$, Gian Zamboni T. ${ }^{3}$ y Claudia Marín H. ${ }^{4}$
}

\section{Endovascular therapy in peripheral trauma: Our experience}

Introduction: Endovascular therapy has proven to be a good treatment alternative in arterial and venous diseases. Likewise, in peripheral vascular trauma it is an excellent option, especially in anatomical sites that are difficult to access and with complex lesions such as pseudoaneurysms, arteriovenous fistulas (AVFs) or the combination of both, with numerous advantages. Aim: To evaluate the results of endovascular treatment in trauma Penetrating vascular injury and iatrogenesis. Materials and Method: Retrospective review of all patients with peripheral vascular trauma undergoing endovascular therapy. Results: Between April 2011 and May 2020, 30 patients were treated, 28 men and 2 women. With fluctuating ages between 17 and 84 years. The cause of the trauma was 20 penetrating and 10 iatrogenic. The affected vessels were superficial femoral artery 6 , deep femoral 2 , subclavian 9 , axillary 1 , popliteal 4 , iliac 1 , peroneal 1 , anterior tibial 5, brachiocephalic venous trunk 1 . Seventeen patients were treated with endoprosthesis, 9 with embolization and 4 with percutaneous closure in relation to arterial catheters in the subclavian. There was no mortality but two patients required open repair: a giant popliteal pseudoaneurysm and an anterior tibial pseudoaneurysm in which both sections of both arteries were found to be complete. Clinical follow-up was between 30 days and 3 years. Conclusion: In this serie, endovascular therapy in peripheral vascular trauma lesions offers excellent results with low morbidity and mortality and acceptable patency in the short and medium term.

Key words: peripheral vascular trauma; endoprosthesis; embolization.

\section{Resumen}

Introducción: La terapia endovascular ha demostrado ser una buena alternativa de tratamiento en las enfermedades arteriales y venosas. Asimismo, en trauma vascular periférico constituye una excelente opción, especialmente en sitios anatómicos difíciles de acceder y con lesiones complejas como seudoaneurismas, fístulas arteriovenosas (FAV) o la combinación de ambos, con numerosas ventajas. Objetivo: Evaluar los resultados del tratamiento endovascular en trauma vascular penetrante por agresiones y iatrogenias. Materiales y Método: Revisión retrospectiva de todos los pacientes con trauma vascular periférico sometidos a terapia endovascular. Resultados: Entre abril de 2011 y mayo de 2020 se trataron 30 pacientes, 28 hombres y 2 mujeres. Con edades fluctuantes entre 17 y 84 años. La causa del trauma fue 20 penetrantes y 10 iatrogenias. Los vasos afectados fueron arteria femoral superficial 6 , femoral profunda 2, subclavia 9, axilar 1 , poplítea 4 , ilíacas 1 , peronea 1 , tibial anterior 5 , tronco venoso braquiocefálico 1. Diecisiete pacientes fueron tratados con endoprótesis, 9 con embolización y 4 con cierre percutáneo en relación con catéteres arteriales en subclavia. No hubo mortalidad, pero dos pacientes requirieron reparación abierta: un seudoaneurisma poplíteo gigante y un seudoaneurisma de tibial anterior, en ambos se constató sección completa de ambas arterias. El seguimiento clínico ha sido entre 30 días y 3 años. Conclusiones: En esta serie de casos, la terapia endovascular en lesiones de trauma vascular periférico ofrece excelentes resultados con baja morbimortalidad y permeabilidad aceptable a corto y mediano plazo.

Palabras clave: trauma vascular periférico; endoprótesis; embolización.
Servicio de Cirugía Hospital de Urgencia Asistencia Pública.

${ }^{2}$ Clinica Indisa.

${ }^{3}$ Radiologo intervencionista Hospital de Urgencia Asistencia Pública.

${ }^{4}$ Alumna Escuela de Medicina, Pontificia Universidad Católica de Chile.

Recibido 2020-06-10 y aceptado 2020-09-21

Correspondencia a: Dr. Juan Marín P. jmarin1953@gmail.com 


\section{Introducción}

Los traumatismos vasculares han sido reparados a través de la cirugía abierta o convencional desde siempre, con buenos resultados, pero no exentos de mortalidad y morbilidad importante asociada ${ }^{1,2}$. En el manejo quirúrgico abierto del trauma vascular nos encontramos con grandes dificultades técnicas: abordaje a través de grandes incisiones, complejas reparaciones en un campo infiltrado con sangre, coágulos, muchas veces en sitios de difícil acceso como ilíacas, región subclavio-axilar, poplíteas y troncos supraaórticos, con el riesgo de lesionar estructuras adyacentes como venas, nervios, vísceras huecas e incluso uréteres en la zona ilíaca. A esto hay que agregarle la pérdida sanguínea que puede ser importante, asociado a la posibilidad de infección vascular que constituye una verdadera catástrofe. En la actualidad ha habido un importante avance desde el punto de vista de la conducta a seguir. Lo único que nos obliga a actuar son las lesiones con sangramiento activo ("stop de bledding") en que la cirugía abierta juega un rol muy importante, pero el resto podemos disponer de imágenes de gran calidad para planear la reparación vascular, incluso frente a una isquemia de la extremidad.

Desde la década de los 90, cuando se inicia el desarrollo de la era endovascular para las diferentes enfermedades arteriales y venosas, aparecen algunos trabajos en que se aplica esta técnica en el manejo del trauma vascular ${ }^{3-5}$. El objetivo de nuestro trabajo es dar a conocer nuestra experiencia y contribuir en el manejo endovascular del trauma periférico.

\section{Material y Método}

Serie retrospectiva de pacientes tratados con técnica endovascular entre abril de 2011 y mayo de 2020. Son 30 pacientes cuyas edades fluctúan entre 17 y 84 años. 28 hombres y dos mujeres. Todos los pacientes fueron estudiados mediante angioTC para diagnosticar las lesiones y el tratamiento se hizo en pabellon híbrido con anestesia local o regional. La gran mayoría son efectuados en el hospital de urgencia por el primer autor. El mecanismo más frecuente fue trauma penetrante, ya sea por arma blanca o de fuego y el otro mecanismo fueron iatrogenias (Tabla 1). En cuanto al tipo de lesiones se identificaron 6 seudoaneurismas de vasos tibiales, 4 seudoaneurismas de arteria subclavia, 4 catéteres puestos en arteria subclavia del tipo venoso central, 1 seudoaneurisma de arteria axilar (Figuras 1 a 5), 2 seudoaneurismas de arteria poplítea, 2 seudoaneuris- mas de femoral profunda, 3 seudoaneurismas de femoral superficial, 2 FAV de vasos poplíteos, 2 FAV asociados a seudoaneurisma de vasos subclavios, 1 seudoanaeurisma de femoral superficial asociado a FAV, 2 catéteres tunelizados para diálisis colocados en arteria subclavia, $1 \mathrm{FAV}$ asociado a vasos iliacos y una lesión de tronco venoso braquiocefálico por catéter tunelizado para diálisis.

En cuanto a tratamiento, los seudoaneurismas de vasos tibiales y de femoral profunda se trataron mediante embolización con coils. El resto de los seudoaneurismas de vasos subclavios, poplítea, axilar y aquellos asociados a FAV se trataron con endoprótesis cubierta (GORER VIABAHNR), a excepcion de la FAV y seudoaneurisma asociado de vasos iliacos que se trató con un stent cubierto del tipo FLUENCY ${ }^{\circledR}$. El catéter tunelizado venoso con lesión transfixiante de tronco venoso braquicefálico fue reparado con stent cubierto también (GoreRVIABAHN). Finalmente, en relación a catéteres venosos colocados en arteria subclavia, en 5 de ellos se utilizó cierre percutáneo para sellar el orificio en la arteria.

\section{Resultados}

El éxito inicial fue de $100 \%$, dos pacientes recidivaron de seudoaneurisma: uno de arteria poplítea gigante por trauma por arma de fuego en que se comprobó que ambos cabos estaban seccionados y separados, lo mismo ocurrió con un seudoaneurisma tibial por arma blanca. Ambos reparados mediante cirugía abierta. No tuvimos mortalidad. El seguimiento ha sido entre 3 años y un mes.

\section{Discusión}

En el manejo quirúrgico abierto del trauma vascular nos encontramos con grandes dificultades técnicas. Especialmente afrontamos grandes dificultades si tratamos seudoaneurismas y FAV, sobre todo de larga data, en que hay un gran crecimiento tanto del seudoaneurisma como del tamaño de la FAV, acompañado de gran circulación colateral venosa, pero con flujo arterial. A todo esto, hay que agregarle la pérdida sanguínea que puede ser importante asociado a la posibilidad de infección vascular que constituye una verdadera catástrofe. En la actualidad ha habido un importante avance desde el punto de vista de la conducta a seguir en el manejo del trauma vascular. Lo único que nos obliga a actuar son las lesiones con sangramiento 
Tabla 1. Resumen de casos

\begin{tabular}{|c|c|c|c|c|c|}
\hline Caso & Edad & Mecanismo & Tipo de lesión y vaso & Tratamiento & Seguimiento \\
\hline 2 & 20 años & Vidrio & Seudoaneurisma - arteria peronea & Embolización con coils & 3 años \\
\hline 3 & 20 años & Arma blanca & Seudoaneurisma - Vasos tibiales & Embolización con coils & 8 meses \\
\hline 4 & 35 años & Arma blanca & Seudoaneurisma - arteria poplítea & Endoprótesis Viabahn ${ }^{\circledR}$ & 1 año \\
\hline 6 & 28 años & Arma de fuego & FAV vasos poplíteos & Endoprótesis Viabahn ${ }^{\circledR}$ & 2 años \\
\hline 7 & 65 años & $\begin{array}{l}\text { Iatrogenia } \\
\text { Catéter }\end{array}$ & Seudoaneurisma - arteria subclavia & Endoprótesis Viabahn ${ }^{\circledR}$ & 1 año \\
\hline 8 & 28 años & Arma de fuego & Seudoaneurisma - arteria subclavia & Endoprótesis Viabahn ${ }^{\circledR}$ & 1 año \\
\hline 11 & 25 años & Arma de fuego & Seudoaneurisma y FAV - femoral superficial & Endoprótesis Viabahn ${ }^{\circledR}$ & 1 año \\
\hline 12 & 84 años & $\begin{array}{c}\text { Iatrogenia } \\
\text { coronariografía }\end{array}$ & Seudoaneurisma - femoral superficial & Endoprótesis Viabahn $^{\circledR}$ & 6 meses \\
\hline 13 & 60 años & $\begin{array}{l}\text { Iatrogenia } \\
\text { Catéter }\end{array}$ & Seudoaneurisma - arteria subclavia & Endoprótesis Viabahn $^{\circledR}$ & 3 meses \\
\hline 14 & 63 años & $\begin{array}{c}\text { Iatrogenia } \\
\text { Catéter tunelizado } \\
\text { Diálisis }\end{array}$ & Lesión arteria subclavia & Endoprótesis Viabahn ${ }^{\circledR}$ & 6 meses \\
\hline 15 & 79 años & $\begin{array}{c}\text { Iatrogenia } \\
\text { Catéter tunelizado } \\
\text { Diálisis }\end{array}$ & Lesión tronco venoso braquiocefálico & Endoprótesis Viabahn $^{\circledR}$ & 45 días \\
\hline 19 & 25 años & Arma de fuego & Seudoaneurisma y FAV subclavia & Endoprótesis Viabahn ${ }^{\circledR}$ & 40 días \\
\hline 20 & 23 años & $\begin{array}{c}\text { Iatrogenia } \\
\text { coronariografía }\end{array}$ & Seudoaneurisma de femoral profunda & Embolización con coils & 40 días \\
\hline 24 & 30 años & Arma de fuego & Seudoaneurisma y FAV de subclavia & Endoprótesis Viabahn ${ }^{\circledR}$ & 30 días \\
\hline 25 & 30 años & Arma de fuego & Seudoaneurisma y FAV femoral & Endoprótesis Viabahn ${ }^{\circledR}$ & 3 meses \\
\hline 26 & 53 años & Iatrogenia & Catéter central en arteria subclavia & Cierre percutáneo Angioseal ${ }^{\circledR}$ & 30 días \\
\hline 27 & 55 años & Iatrogenia & Catéter central en arteria subclavia & Cierre percutáneo Angioseal ${ }^{\circledR}$ & 30 días \\
\hline 28 & 56 años & Iatrogenia & Catéter central en arteria subclavia & Cierre percutáneo Angioseal ${ }^{\circledR}$ & 30 días \\
\hline 29 & 54 años & Iatrogenia & Catéter central en arteria subclavia & Cierre percutáneo Angioseal ${ }^{\circledR}$ & 30 días \\
\hline 30 & 57 años & Iatrogenia & Catéter central en arteria subclavia & Cierre percutáneo Angioseal ${ }^{\circledR}$ & 30 días \\
\hline
\end{tabular}



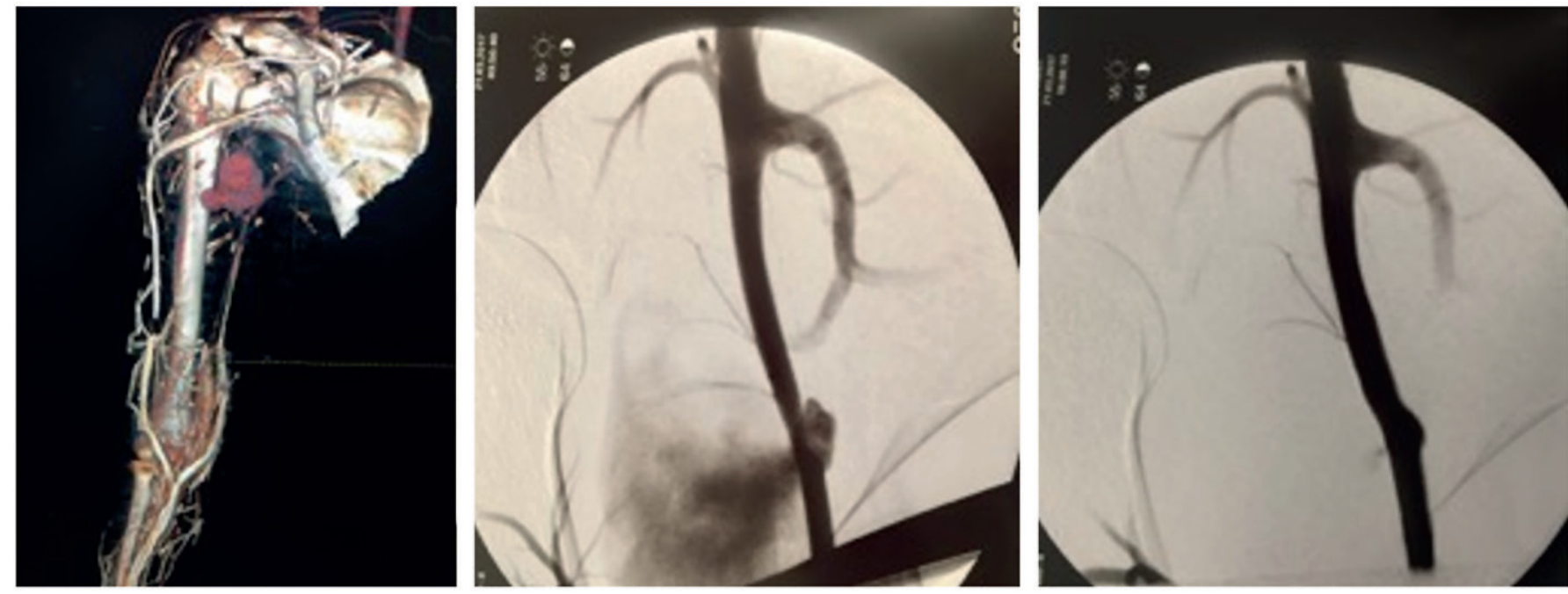

Figura 1. Seudoaneurisma de arteria axilar por arma blanca: reparación con stent cubierto.
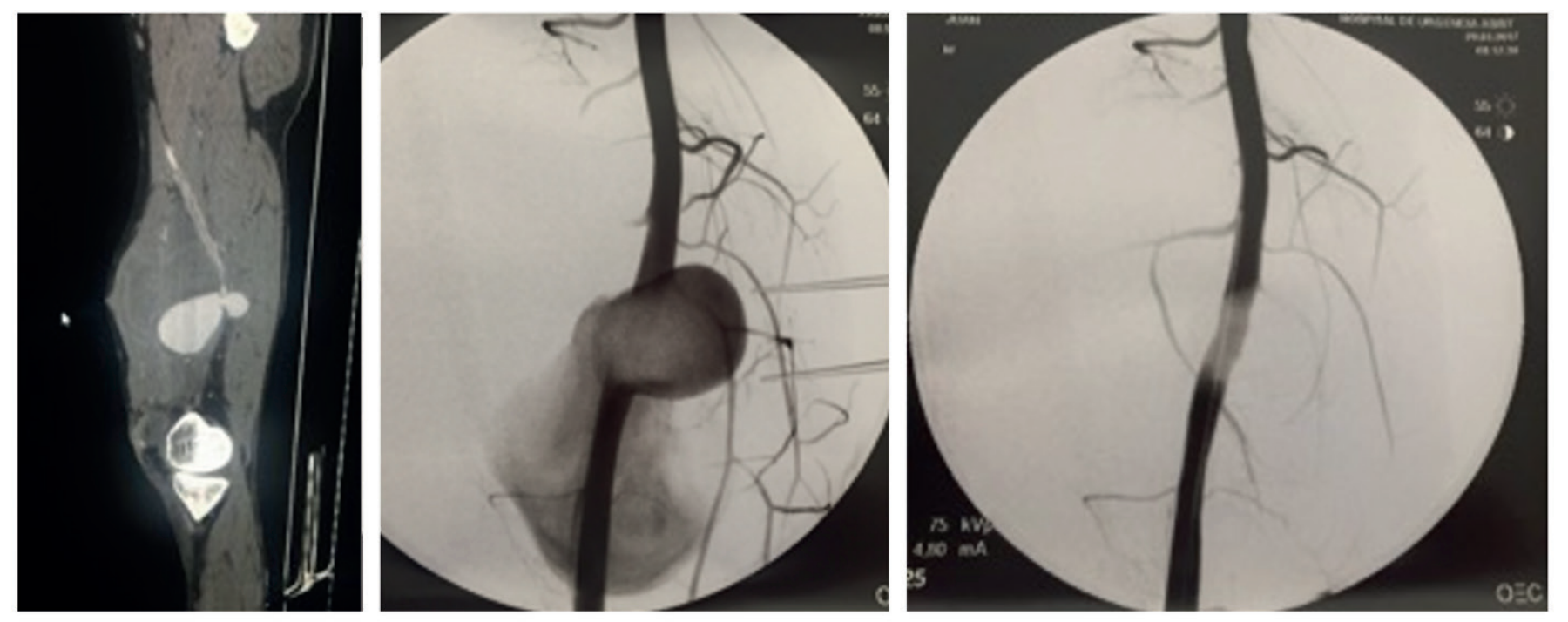

Figura 2. Seudoaneurisma de arteria femoral superficial por arma blanca reparado con stentgraft

activo ("stop de bledding") en que la cirugía abierta juega un rol muy importante, pero el resto podemos disponer de imágenes de gran calidad para planear la reparación vascular incluso frente a una isquemia de la extremidad y complicaciones como seudoaneurismas y FAV, o la asociación de ambos. A pesar de estos problemas la cirugía abierta logra obtener buenos resultados, pero con morbimortalidad no despreciable ${ }^{1,2}$. Particularmente, si se analizan los catéteres centrales colocados en la arteria subclavia por equivocación, al inicio de esta experiencia usabamos stentgraft para evitar el sangrado o la presencia de un seudoaneurisma. Como alternativa se puede usar un balón de angioplastía para sellar el orificio, ya sea uno o que la arteria sea transfixiada. Hoy en día estamos usando cierres percutáneos (Angioseal $\left.^{\circledR}\right)$. Si bien, estos cierres percutáneos han sido originalmente usados en intervenciones endovasculares para sellar entrada en arteria femoral, creemos que es una alternativa aceptable para usar en estos catéteres centrales colocados en arteria subclavia.

En relación con la cirugía endovascular, si bien 


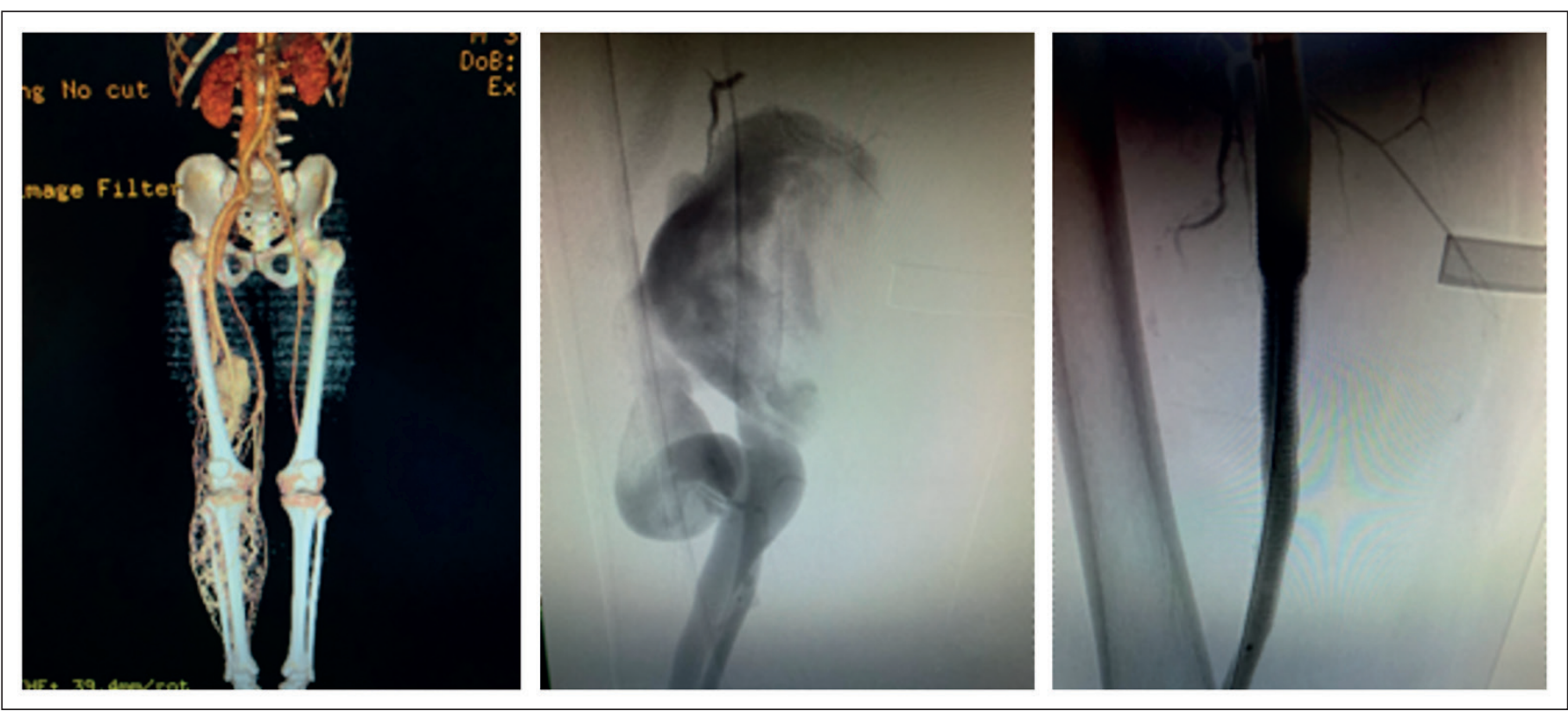

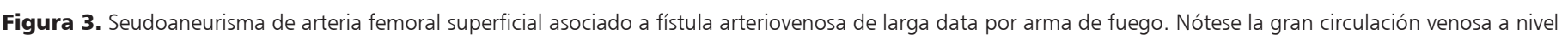
de pierna. Reparación con stent cubierto.

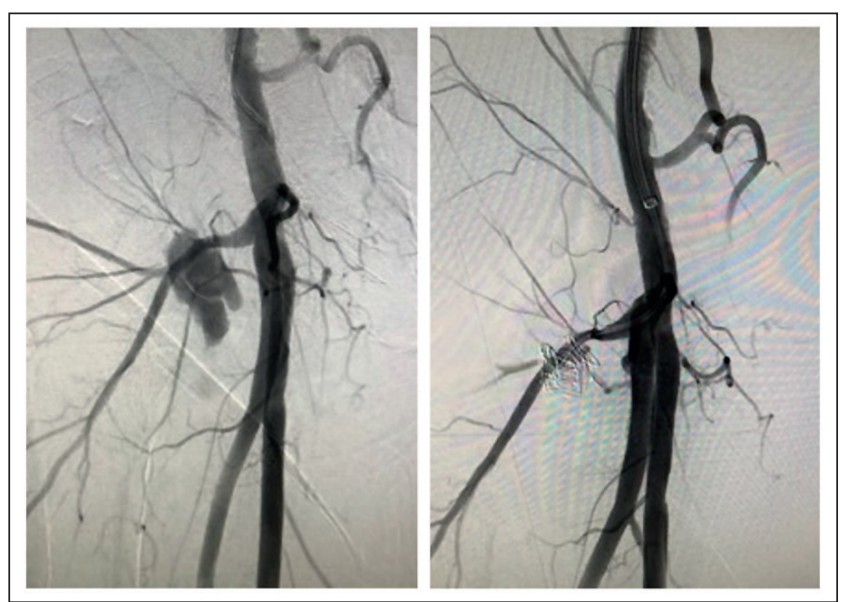

Figura 4. Reparación de seudoaneurisma secundario a coronariografía de rama femoral con coils.

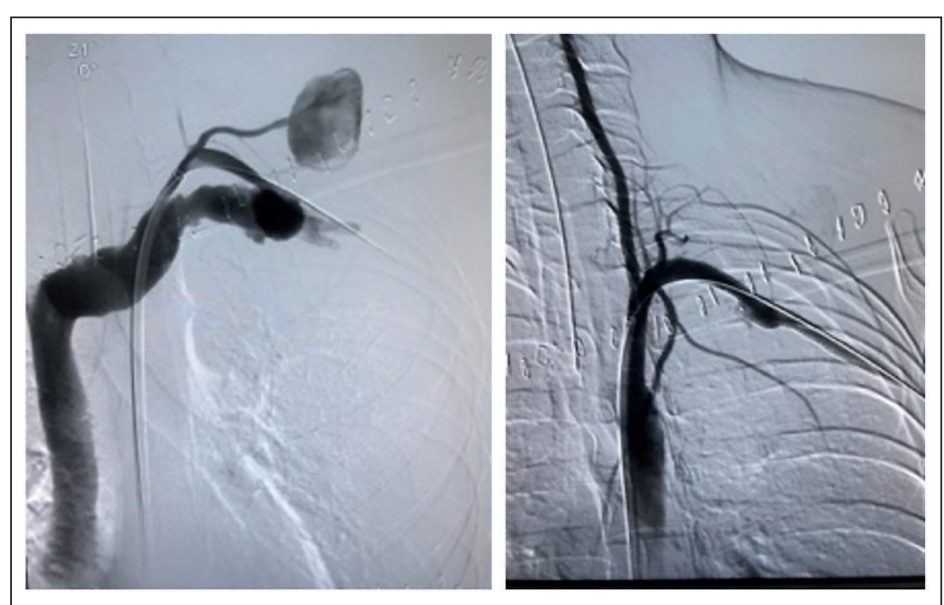

Figura 5. Fístula arteriovenosa y seudoaneurisma de vasos subclavios por arma de fuego. Reparación con stentgraft. al comienzo se ideó para patologías arteriales del tipo aneurisma y enfermedad arterial oclusiva, en trauma comenzaron a aparecer lesiones tratadas con esta técnica, especialmente en grandes vasos como aorta $^{6,7}$. En trauma periférico inicialmente se trataron pacientes de alto riesgo quirúrgico ${ }^{3,4,8}$. Pero hoy en dia, ya hay numerosas publicaciones para tratar trauma, si bien, son pequeñas series ${ }^{9}$.

En nuestros casos el uso de stentgraft fue utilizado para tratar vasos de gran calibre que presentaban roturas, seudoaneurismas, FAV o lesiones asociadas.
En vasos pequeños los embolizamos con coils. No creemos que el uso de stentgrafts sea útil en vasos pequeños por su corta permeabilidad y mayor riesgo de infección por ser lesiones con arma blanca.

\section{Conclusiones}

La terapia endovascular ofrece numerosas ventajas con cero mortalidad y escasa morbilidad en el tratamiento del trauma vascular periférico, pero requiere de personal entrenado y los materiales ade- 
cuados con un pabellón híbrido. Siendo una serie de casos, dicho diseño limita las conclusiones. Debido a que la gran mayoría de estos pacientes son jóvenes no sabemos cuál será la permeabilidad a largo plazo, sin embargo, en caso de oclusión o recidiva de estas lesiones nos permitirá efectuar una reparación abierta en un campo de mejor calidad sin los inconvenientes que presenta la cirugía tradicional en etapa aguda.

\section{Responsabilidades éticas}

Protección de personas y animales. Los au- tores declaran que para esta investigación no se han realizado experimentos en seres humanos ni en animales.

Confidencialidad de los datos. Los autores declaran que en este artículo no aparecen datos de pacientes.

Conflictos de interés: no hay.

Financiamiento: Este estudio no contó con financiamiento de empresas externas ni reciben los autores financiamiento por parte de empresas privadas.

\section{Bibliografía}

1. Perry MO, Thal ER, and Shires GT: Management of arterial injuries. Ann Surg. 1971;173:403-8.

2. Drapanas T, Hewitt RL, Weichert RF, Smith AD. Civilian vascular injuries: A critical appraisal of three decades of management. Ann Surg. 1970;172:351-60.

3. Marin ML, Veith FJ, Panetta TF, Cynamon J, Sánchez LA, Schwartz ML, et al. Transluminally placed endovascular stented graft repair for arterial trauma. J Vasc Surg. 1994;20:466-72; discussion 472-3.
4. May J, White G, Waugh R, Yu W, Harris J. Transluminal placement of a prosthetic graft-stent device for treatment of subclavian artery aneurysm. J Vasc Surg. 1993;18:1056-9.

5. Parodi JC, Schonholz C, Ferreira LM, Bergan J. Endovascular stent-graft treatment of traumatic arterial lesions. Ann Vasc Surg. 1999;13:121-9.

6. Shan JG, Zhai XM, Liu JD, Yang WG, Xue S. Thoracic Endovascular Aortic Repair for Traumatic Thoracic Aortic Injury: A Single-Center Initial Experience. Ann Vasc Surg. 2016;32:104-10.

7. Bent CL, Matson MB, Sobeh M,
Renfrew I, Uppal R, Walsh M, et al. Endovascular Management of Acute Blunt Traumatic Thoracic Aortic Injury: A Single Center Experience. J Vasc Surg. 2007;46:920-7.

8. Marín ML, Veith FJ, Panetta TF, Cynamon J, Barone H, Schonholz C, et al. Percutaneous transfemoral insertion of a stented graft to repair a traumatic femoral arteriovenous fistula. J Vasc Surg. 1993;18:299-302.

9. Jacks R, Degiannis E. Endovascular Therapy and Controversies in The Management of Vascular Trauma. Scand J Surg. 2014;103:149-55. 